\title{
GCU
}

Glasgow Caledonian

University

University for the Common Good

\section{Pharmaceuticals removal and nutrient recovery from wastewaters by Chlamydomonas acidophila}

Escudero, Ania; Hunter, Colin; Roberts, Joanne; Helwig, Karin; Pahl, Ole

Published in:

Biochemical Engineering Journal

DOI:

10.1016/j.bej.2020.107517

Publication date:

2020

Document Version

Author accepted manuscript

Link to publication in ResearchOnline

Citation for published version (Harvard):

Escudero, A, Hunter, C, Roberts, J, Helwig, K \& Pahl, O 2020, 'Pharmaceuticals removal and nutrient recovery from wastewaters by Chlamydomonas acidophila', Biochemical Engineering Journal, vol. 156, 107517. https://doi.org/10.1016/j.bej.2020.107517

\section{General rights}

Copyright and moral rights for the publications made accessible in the public portal are retained by the authors and/or other copyright owners and it is a condition of accessing publications that users recognise and abide by the legal requirements associated with these rights.

Take down policy

If you believe that this document breaches copyright please view our takedown policy at https://edshare.gcu.ac.uk/id/eprint/5179 for details of how to contact us. 
1 PHARMACEUTICALS REMOVAL AND NUTRIENT RECOVERY FROM

1

2 WASTEWATERS BY CHLAMYDOMONAS ACIDOPHILA

3 Author names and affiliations:

4 Ania Escudero, Colin Hunter, Joanne Roberts, Karin Helwig, Ole Pahl.

5 GLASGOW CALEDONIAN UNIVERSITY, Cowcaddens Road, Glasgow, G4 0BA,

6 Scotland, UK

7 Corresponding author: Ania Escudero

8 GLASGOW CALEDONIAN UNIVERSITY, Cowcaddens Road, Glasgow, G4 0BA,

9 Scotland, UK

10 ania.escudero@gcu.ac.uk / ania.es.ol@gmail.com

$11+00441413318501$ 


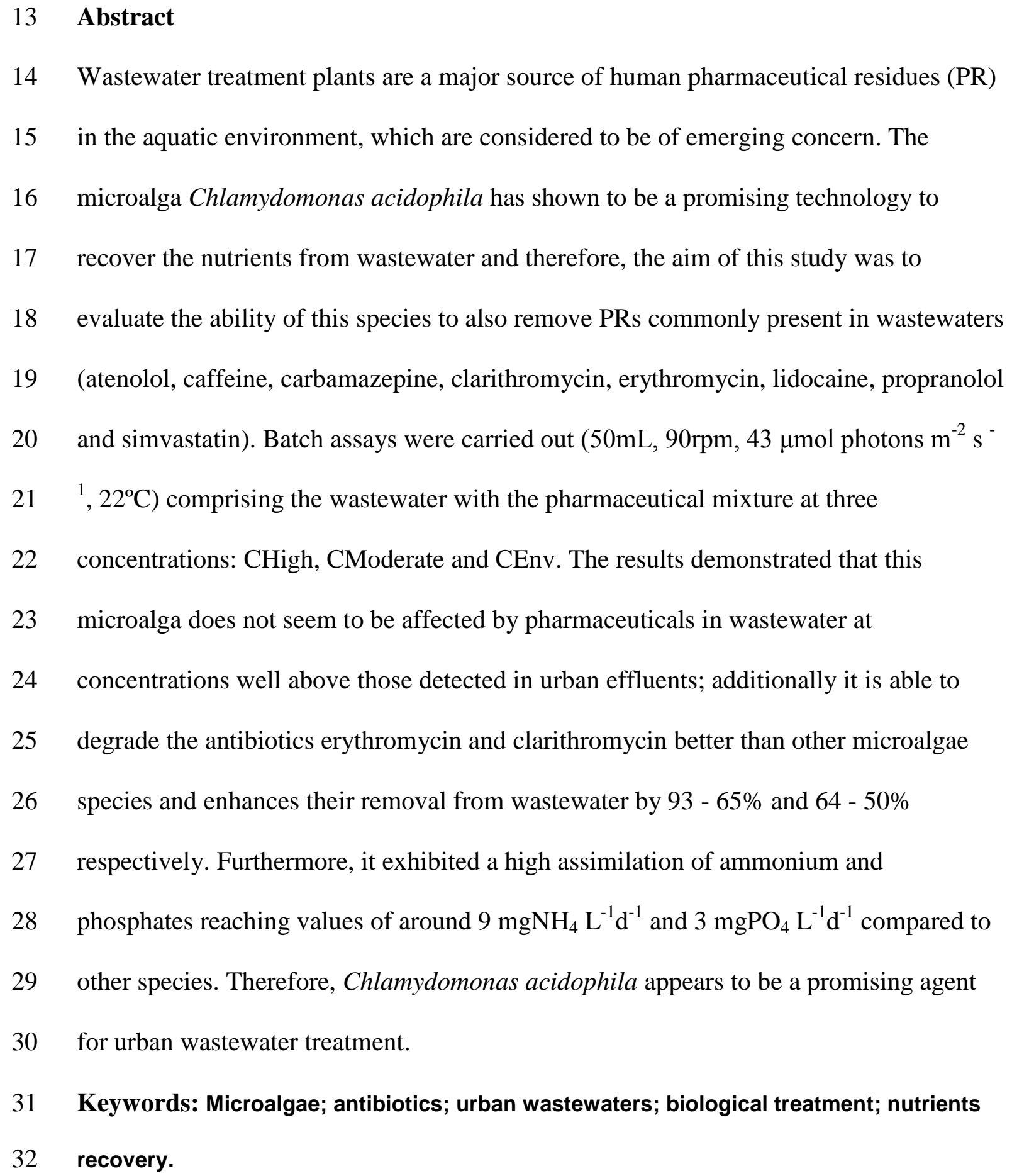

14 Wastewater treatment plants are a major source of human pharmaceutical residues (PR)

15 in the aquatic environment, which are considered to be of emerging concern. The

16 microalga Chlamydomonas acidophila has shown to be a promising technology to

17 recover the nutrients from wastewater and therefore, the aim of this study was to

18 evaluate the ability of this species to also remove PRs commonly present in wastewaters

19 (atenolol, caffeine, carbamazepine, clarithromycin, erythromycin, lidocaine, propranolol

20 and simvastatin). Batch assays were carried out $\left(50 \mathrm{~mL}, 90 \mathrm{rpm}, 43 \mu \mathrm{mol}\right.$ photons $\mathrm{m}^{-2} \mathrm{~s}^{-}$

$21{ }^{1}, 22^{\circ} \mathrm{C}$ ) comprising the wastewater with the pharmaceutical mixture at three

22 concentrations: CHigh, CModerate and CEnv. The results demonstrated that this

23 microalga does not seem to be affected by pharmaceuticals in wastewater at

24 concentrations well above those detected in urban effluents; additionally it is able to

25 degrade the antibiotics erythromycin and clarithromycin better than other microalgae

26 species and enhances their removal from wastewater by $93-65 \%$ and $64-50 \%$

27 respectively. Furthermore, it exhibited a high assimilation of ammonium and

28 phosphates reaching values of around $9 \mathrm{mgNH}_{4} \mathrm{~L}^{-1} \mathrm{~d}^{-1}$ and $3 \mathrm{mgPO}_{4} \mathrm{~L}^{-1} \mathrm{~d}^{-1}$ compared to

29 other species. Therefore, Chlamydomonas acidophila appears to be a promising agent

30 for urban wastewater treatment.

31 Keywords: Microalgae; antibiotics; urban wastewaters; biological treatment; nutrients

32 recovery. 


\section{1. Introduction}

34 In recent years there has been increasing scientific and regulatory attention towards emerging micro-pollutants such as pharmaceutical residues in the aquatic environment. Pharmaceutical residues (PR) can originate from agricultural activities, hospital effluents, industrial wastes and domestic wastes. They are typically found at very low concentrations in the environment and are unlikely to affect human health but could cause chronic exposure damage to aquatic organisms [1,2]. In addition, the continually pharmaceuticals consumption is set to increase, necessitating continual review of risk assessments [3].

Following human consumption, PR are generally excreted into the sewer and subsequently reach wastewater treatment plants (WWTPs), where they are not fully removed [4,5]. Thus, WWTP are a major source of human PR in the aquatic environment, at least in regions where most properties are connected to the sewer.

Reflecting growing concerns regarding the environmental impact of PR, the European

Commission added the macrolide antibiotics (erythromycin, clarithromycin and azithromycin) to its 'Watch List' in 2015. This list, first introduced in 2013, requires union-wide monitoring of substances that are suspected of posing an environmental risk but for which insufficient monitoring data is available to determine their actual environmental risk. Two more antibiotics, ciprofloxacin and amoxicillin, were added in 2018 [6]. As pharmaceutical substances are designed to be bio-active, they can have very low predicted no-effect concentrations above which they may pose ecotoxicological risks. Their continuous input leads to pseudo-persistence in the environment. Additionally, the presence of five antibiotics in the new Watch List aligns with the European One Health Action Plan against Antimicrobial Resistance (AMR), 
58 which supports the use of the Watch List to "improve knowledge of the occurrence and 59 spread of antimicrobials in the environment".

60 Nearly a century after the discovery of penicillin, the global population is experiencing 61 widespread treatment failure from previously treatable bacterial infections. This crisis 62 stems from chronically poor antibiotic stewardship in the clinical and veterinary/animal 63 husbandry setting, which is further compounded by ubiquitous environmental pollution 64 of antibiotics and antibiotic resistant genes from industry, sewage and manure [7]. 65 Upon consumption, most antibiotics are partly metabolised, with a fraction of the consumed 66 amount excreted into the sewer as parent compound. These residues, along with any 67 metabolites, thus reaches WWTP, where some are resistant to conventional physico-chemical 68 and biological processes and are only partially removed [8]. Subsequently, antibiotics will 69 enter the receiving river [9], from which they can exert a selective pressure for resistant 70 genes and potentially give rise to AMR. In fact, the conditions in conventional 71 biological wastewater treatment can - in themselves - induce increased development of 72 antibiotic resistance due to the co-existence of various environmental stressors and pre73 existing antibiotic resistance genes [10].

74 Although several advanced treatment technologies are available for removing PRs, the 75 low removal efficiencies or financial and technical limitation of the application of these 76 technologies in wastewater treatment continue to drive research for better treatment 77 strategies for the removal of these PRs [2].

78 Among new developments in biological wastewater treatment, microalgae are used 79 around the world for the removal of nutrients from different waste effluents.

80 Chlamydomonas acidophila have been shown as promising agents for the removal and 81 recovery of nutrients from effluents in North-West Europe and similar climatic regions, 82 as they can operate at low temperatures and low light intensity and is able to tolerate 83 very high ammonium concentrations of up to $1000 \mathrm{mg} \mathrm{NH}_{4}-\mathrm{N} \mathrm{L}^{-1}$ [11]. Additionally, 
84 mixotrophic algae, such as C. acidophila, have an additional benefit applicable in wastewater treatment, in that they can switch their metabolism between autotrophic and heterotrophic mode depending on the availability of carbon sources and nutrients in the surrounding environment, which provides them a great flexibility to survive and thrive in variable and extreme conditions [2,12-14]. However, no information is available regarding their potential for removing pharmaceuticals, or on the impact of pharmaceuticals on their growth and functioning.

This paper investigates the use of Chlamydomonas acidophila in addressing three concurrent needs to develop improved wastewater treatment techniques: removal of nutrients, pharmaceuticals generally, and antibiotics specifically. Therefore, the aims of this study were to investigate the growth and nutrient consumption of Chlamydomonas acidophila in an anaerobically pre-treated wastewater containing different pharmaceuticals and to determine the ability of this species to remove these micropollutants. The anaerobic effluent, as may arise from digestate of sewage sludge, was chosen due to the twin problem of high nutrient concentration (AD does not remove nutrients) and pharmaceutical residues including a range of antibiotic substances.

\section{Materials and methods}

\subsection{Microorganisms and culture conditions}

The strain of Chlamydomonas acidophila used in the study was obtained from the Göttingen collection of algae for culture (Sammlug von Algenkulturen Göttingen [SAG], Germany). Cells used for the inoculum were grown in bottles of constant working volume $1 \mathrm{~L}$ (ensured by addition of distilled water to replace water lost by evaporation), which was maintained at room temperature and light conditions, bubbled with air. 
108 The microalgae were maintained by periodic transfer to a standard medium (SM)

109 containing the following ingredients: $\left(\mathrm{NH}_{4}\right)_{2} \mathrm{SO}_{4}\left(1000 \mathrm{mg} \mathrm{L}^{-1}\right), \mathrm{K}_{2} \mathrm{HPO}_{4}\left(200 \mathrm{mg} \mathrm{L}^{-1}\right)$,

$110 \mathrm{MgSO}_{4}\left(20 \mathrm{mg} \mathrm{L}^{-1}\right), \mathrm{Na} 2 \mathrm{EDTA}\left(130 \mathrm{mg} \mathrm{L}^{-1}\right), \mathrm{FeSO}_{4} \cdot 7 \mathrm{H}_{2} \mathrm{O}\left(80 \mathrm{mg} \mathrm{L}^{-1}\right), \mathrm{MnCl}_{2} \cdot 4 \mathrm{H}_{2} \mathrm{O}$

$111\left(0.18 \mathrm{mg} \mathrm{L}^{-1}\right), \mathrm{ZnCl}_{2}\left(0.052 \mathrm{mg} \mathrm{L}^{-1}\right)$, and $\mathrm{Na}_{2} \mathrm{MoO}_{4} \cdot 2 \mathrm{H}_{2} \mathrm{O}\left(0.063 \mathrm{mg} \mathrm{L}{ }^{-1}\right)$. The cells

112 were harvested and separated from the media by centrifugation at $2500 \mathrm{rpm}$ for $3 \mathrm{~min}$.

113 The separated cells were washed 3 times with distilled water and the centrifugation step

114 was repeated to remove all culture medium prior to use in the different assays.

\section{2.2. Wastewater}

116 Among the processes used for wastewater treatment (WWT), anaerobic processes have

117 the advantage of reducing the organic matter of municipal and industrial wastewaters

118 producing energy at the same time [15]. Furthermore, complex organic nitrogen and

119 phosphorus compounds are mineralized to $\mathrm{NH}_{4}-\mathrm{N}$ and $\mathrm{PO}_{4}-\mathrm{P}$ during $\mathrm{AD}$ [16], which are

120 key nutrients for controlled (remediation processes) and uncontrolled (eutrophication)

121 growth of microalgae. Given the extensive use of anaerobic digestion associated with

122 WWT in the UK and the drive to reduce nutrient pollution of water bodies via various

123 directives [Urban Wastewater Treatment (91/271/EEC) [17]; Nitrates (91/676/EEC)

124 [18] and Water Framework (2000/60/EC) [19] Directives] nutrient rich anaerobically

125 treated wastewater is an important waste steam both for nutrient and pharmaceutical

126 pollution. Therefore, for the present study, anaerobically treated wastewater was used in

127 the assays carried out.

128 In order to provide consistent conditions for these experiments, artificial wastewater

129 effluent was generated in the laboratory by anaerobic digestion of a synthetic

130 wastewater adapted from the Organization for Economic Cooperation and Development

131 [20], to simulate the constituents of typical wastewater: tryptone $350 \mathrm{mg} \mathrm{L}^{-1}$, meat

132 extract $110 \mathrm{mg} \mathrm{L}^{-1}, \mathrm{~K}_{2} \mathrm{HPO}_{4} 28 \mathrm{mg} \mathrm{L}^{-1}, \mathrm{NaCl} 7 \mathrm{mg} \mathrm{L}^{-1}, \mathrm{CaCl}_{2} 3 \mathrm{mg} \mathrm{L}^{-1}$ and $\mathrm{MgSO}_{4} 2 \mathrm{mg}$ 
$133 \mathrm{~L}^{-1}$. The synthetic wastewater was digested in a $6 \mathrm{~L}$ volume completely mixed anaerobic

134 bioreactor maintained at a temperature of $35^{\circ} \mathrm{C}$, loading rate of $0.9 \mathrm{~g} \mathrm{~L}^{-1} \mathrm{~d}^{-1}$ of volatile

135 solids (VS) and a hydraulic retention time (HRT) of 4 days. In order to retain the solids

136 in the system, stirring was stopped 15 min before feeding and effluent extraction, so that

137 the solids could settle and effluent be removed from the liquid phase. The effluent was

138 stored at $4^{\circ} \mathrm{C}$ prior to the assays.

139 Chemical Oxygen Demand (COD), $\mathrm{pH}, \mathrm{NH}_{4}$ and $\mathrm{PO}_{4}$ contents of the anaerobically

140 treated effluent were around $250 \mathrm{mg} / \mathrm{L}, 6.8,110 \mathrm{mg} \mathrm{L}^{-1}$ and $30 \mathrm{mg} \mathrm{L}^{-1}$ respectively.

$141 \quad$ 2.4. Experimental set-up

142 2.4.1. Removal and influence of the different pharmaceuticals on growth and nutrient

143 recovery of $\mathrm{C}$. acidophila

144 Batch assays were carried out in an orbital incubator shaker, in which cultures of $50 \mathrm{~mL}$

145 were stirred at $90 \mathrm{rpm}$ in $250 \mathrm{~mL}$ glass Erlenmeyer flasks at $22^{\circ} \mathrm{C}$. The surface of the

146 flasks was continuously illuminated, at a rate of approximately $43 \mu \mathrm{mol}$ photons $\mathrm{m}^{-2} \mathrm{~s}^{-1}$

147 by LED lights.

148 Eight different PR were selected based on consumption patterns, ecotoxicity,

149 therapeutic class, regulatory relevance, and availability of an analytical method in the

150 laboratory, and studied at different concentrations (Table 1).

151 Reported concentrations of these PRs in urban wastewater were gathered and, in a first

152 phase (Phase 1), in order to stress the system, the concentrations added to the

153 wastewater were increased 1000 times from both the lowest and the highest

154 concentrations found in literature (CModerate and CHigh, respectively). A second batch

155 test (Phase 2) was also carried out to study the removal and influence of these PRs

156 under environmentally relevant concentrations, where the highest reported

157 concentrations were added to the wastewater (CEnv). 
159 All samples were incubated in triplicate: Standard growing medium with microalgae

160 (SM), a Control sample (the wastewater with microalgae) (WW) and samples

161 comprising the wastewater with the pharmaceutical mixtures at the 3 concentrations

162 (CHigh, CModerate and CEnv) with and without microalgae. Abiotic batches were set

163 up to test for any non-biological micropollutant removal or degradation. Furthermore,

164 because PRs were dissolved in methanol before their addition to the wastewater and this

165 compound might affect the microalgae behaviour, a sample containing wastewater,

166 microalgae and methanol (the same volume as added in CHigh) was included

167 (WW+Met).

168 The flasks containing microalgae were inoculated from the seed culture with $2.5 \times 106$

169 cells $\mathrm{mL}^{-1}$. Cell numbers, and PR, ammonium and phosphate concentrations were

170 measured every $2-3$ days in each sample during the incubation period (14 days). Two

171 subsamples were collected each sampling day. Both samples were centrifuged at 13,000

$172 \mathrm{rpm}$ for $3 \mathrm{~min}$ and one was stored at $4{ }^{\circ} \mathrm{C}$ until nutrients analysis and the second one was

173 stored at $-20^{\circ} \mathrm{C}$ until PR analysis.

174 2.4.2. Subsequent experiments on the removal of the antibiotics

175 Because significant removal of the antibiotics was observed during the initial batch experiments, the antibiotics erythromycin and clarithromycin were studied separately

177 using standard growing media (SM), in order to evaluate their removal without any

178 interference from other PR or wastewater constituents. Assays were carried out under

179 the same operational conditions as the main experiments, in triplicate and over an

180 incubation period of 7 days. The two antibiotics were studied separately, in a mix of SM

181 and under the environmentally relevant concentrations of 2.3 and $8 \mu \mathrm{g} \mathrm{L}^{-1}$ of

182 erythromycin and clarithromycin, respectively. 
184 The $\mathrm{pH}$, total solids (TS) content and VS content were determined according to the

185 Standard Methods for the Examination of Water and Wastewater [36]. The cells

186 concentration in the assays was measured using Celeromics Technologies S.L Micro

187 Counter®. Determination of $\mathrm{NH}_{4}{ }^{+}$in the samples was carried out according to a

188 colorimetric method the colorimetric method based on the Nessler protocol [37]. The

189 standard method $4500 \mathrm{P}-\mathrm{E}$ was used for $\mathrm{PO}_{4}{ }^{3-}$ analysis [36]. Samples were centrifuged

190 at $13,000 \mathrm{rpm}$ for $3 \mathrm{~min}$ before $\mathrm{NH}_{4}{ }^{+}$and $\mathrm{PO}_{4}{ }^{3-}$ analysis.

\section{2.5. Pharmaceuticals analysis}

192 The mass spectrometer used for the pharmaceuticals analysis was a Thermo Scientific

193 Q-exactive Orbitrap mass spectrometer, fitted with a Dionex Ultimate 3000 RS pump,

194 Dionex Ultimate $3000 \mathrm{RS}$ autosampler (temperature controlled at $10^{\circ} \mathrm{C}$ ) and Dionex

195 Ultimate $3000 \mathrm{RS}$ column compartment (temperature controlled at $30^{\circ} \mathrm{C}$ ). The operating

196 software was Chromeleon, Xcalibur and Tracefinder. In both positive and negative

197 ionisation mode the electrospray conditions were sheath gas 45 arbitrary units, auxiliary

198 gas 10 arbitrary units, capillary and auxilliary gas temperature $300^{\circ} \mathrm{C}$. The spray voltage

199 was set at $3.5 \mathrm{kV}$ and $-4.5 \mathrm{kV}$ in positive and negative mode respectively. The

200 pharmaceuticals were detected in positive or negative mode using parallel reaction

201 monitoring using the transitions described in "Supplementary information".

202 The mobile phase for the LC separation was $\mathrm{A}=$ acetonitrile, $\mathrm{B}=10 \mathrm{mmol}$ ammonium

203 formate in water adjusted to $\mathrm{pH} 3.5$ with formic acid) The gradient LC conditions were:

$20499 \%$ B for 1 minute then up to $70 \%$ B over 1 minute. Maintained at $70 \%$ B for 5 minutes

205 then up to $1 \% \mathrm{~B}$ over a further 1 minute. The gradient was maintained at $1 \% \mathrm{~B}$ for a

206 further 3 minutes, back to $99 \%$ B over 1 minute and re-equilibrated with $99 \%$ B for 8

207 minutes. The flow was $0.2 \mathrm{~mL} \mathrm{~min}^{-1}$ and the injection volume was $10 \mu \mathrm{L}$. 
208 Samples were centrifuged at 13,000 rpm for $3 \mathrm{~min}$ and the supernatant was filtered

209 through a $0.2 \mu$ m nylon syringe filter ready for PR analysis in the liquid phase.

210 Once the supernatant was removed, for the analysis of the antibiotics adsorbed to the

211 cell surface, $0.5 \mathrm{~mL}$ water was added to the pellet which was vortexed and centrifuged

212 again before adding a further $0.5 \mathrm{~mL}$ methanol and repeating the procedure of vortexing

213 and centrifugation. The pellet remaining after the methanol wash was re-suspended in

214 methanol $(0.5 \mathrm{~mL})$. After centrifugation the supernatant was removed, dried under a

215 stream of nitrogen at room temperature, re-constituted in $0.5 \mathrm{ml}$ of acetonitrile:water

216 (30:70) and filtered through a $0.2 \mu \mathrm{m}$ nylon syringe filter ready for analysis.

217 The concentration of antibiotics accumulated in the cells were analysed by a disruption

218 of the cells adding glass beads to the remaining pellet and mixed at $6.5 \mathrm{~m} \mathrm{~s}^{-1}$ for 60

219 seconds in a bead beater; this was repeated another 9 times. After centrifugation the

220 supernatant was removed and prepared for analysis following the same procedure as

221 before.

222 2.6. Statistical analysis

223 Tests for significant differences between the samples in the study parameters were

224 performed using SPSS 15.0 for Windows. One-way ANOVA was used when the data

225 were not compared over time. After checking the data for homocedasticity and normal

226 distribution of the variances, the LSD test was used for multiple average comparisons

227 and for detection of any differences between pairs of variables. Differences were

228 considered significant at $\mathrm{p}<0.05$.

229 3. Results and discussion

230 3.1. Removal of pharmaceuticals during the incubation of $\mathrm{C}$. acidophila

231 Removal rates differed significantly depending on the pharmaceutical studied. On the

232 one hand, the concentration of some compounds like caffeine and simvastatin decreased 
233 abruptly in the first days of incubation at the 3 different concentrations (CHigh,

234 CModerate and CEnv) regardless of the presence of the microalgae. On the other hand,

235 compounds like carbamazepine and lidocaine were more persistent and their removal

236 was non-existent (Figure 1).

237 The high caffeine elimination in the samples coincides with the results obtained in other

238 studies. Some authors concluded that caffeine is not photodegradable and therefore,

239 biodegradation seem to be the significant means of caffeine removal $[38,39]$. According

240 to Matamoros et al. [38], caffeine is removed more easily by the combined presence of

241 microalgae and wastewater because of the presence of bacteria in the wastewater and

242 the activity of microalgae. In the present study, the decrease of caffeine concentration

243 was so abrupt in all the samples that we could not observe any differences between

244 them. Regarding simvastatin, in CModerate, the initial concentration added in the

245 samples was $900 \mu \mathrm{g} \mathrm{L-1}$ but the measured concentration at $\mathrm{t}_{0}$ was $2 \mu \mathrm{g}$ L-1 (Figure 1).

246 This similar low concentration for simvastatin at $\mathrm{t}_{0}$ was also observed for the CEnv and

247 CHigh (data not shown). Further investigation of the literature reported simvastatin to

248 be unstable under aqueous conditions and readily forms an acid moiety from the

249 lactone. This is minimised between $\mathrm{pH} 4$ and 5 [40] but not eliminated. Despite the

250 samples being frozen after removal from the reactor they still contain water and hence

251 simvastatin will still degrade. This would explain its low initial concentration and

252 complete removal from the media.

253 FIGURE 1

254 The removal patterns of carbamazepine and lidocaine were similar at the 3 different

255 concentrations and in samples with and without microalgae (final concentrations were

256 not significantly different), which means that they are resistant to biodegradation under

257 aerobic conditions. Furthermore, in agreement with previously published studies, the 
258 photodegradation, biodegradation and sorption of these compounds seem to be

259 negligible [32,41,42]. Therefore, these compounds were not removed.

260 With regard to atenolol and propranolol, under aerobic conditions, the speciation of

261 these ionisable compounds changes influencing their photolysis, leading to their

262 removal due to phototransformation [43]. In the present study, the low $\mathrm{pH}$ in the

263 medium might thus be the reason why very little removal of these compounds was

264 observed.

265 FIGURE 2

266 Previous studies have found, in addition to biotransformation, photolysis appears to be a

267 major removal mechanism in algal treatment systems; unlike most other biological

268 treatment processes, algal treatment increases the removal of the light-sensitive

269 micropollutants due to the illumination of the system [42].

270 In the present study, regardless of their initial concentration (CHigh1000, CLow1000

271 and CEnv), removals of caffeine, simvastatin, carbamazepine, lidocaine, atenolol and

272 propranolol were similar in all cases, which seems to be attributed to bio- or

273 phototransformation. Limited previous studies have found that algal strains can induce

274 biotransformation or biodegradation of chemicals [44].

275 By contrast, the antibiotics erythromycin and clarithromycin appeared to be affected by

276 the presence of the microalgae in the media, where their removal was higher than in

277 samples without microalgae for CEnv and CModerate concentrations (Figure 2). At the

278 highest concentrations of pharmaceuticals (CHigh), the microalgae were strongly

279 inhibited (see 3.2.), and therefore, no significant differences in these antibiotics

280 removals were observed in samples with or without microalgae.

281 Removal of erythromycin was $93 \%$ and $65 \%$ higher and removal of clarithromycin 50

282 and $64 \%$ higher in the samples with microalgae, compared to samples without 
283 microalgae (at CEnv and CModerate respectively). Therefore, it seems that

284 Chlamydomonas acidophila enhanced erythromycin and clarithromycin removals in

285 wastewater. These values are slightly higher for erythromycin and similar for

286 clarithromycin than the improved removals by microalgae reported by Zhou et al. [44]

287 using C. reinhardtii, S. obliquus, C. pyrenoidosa and C. vulgaris, and by Hom-Diaz et

288 al. [45] using a local non-identified microalgae community.

289 The antibiotics experiments were repeated in order to better understand the mechanisms

290 involved. Removal and effect of erythromycin and clarithromycin were monitored in

291 isolation from those of the other PRs and using growing media instead of wastewater to

292 avoid any interference. The same patterns were observed, where $C$. acidophila removed

293 around a $60 \%$ and $80 \%$ more erythromycin and clarithromycin respectively compared to

294 samples without microalgae. Therefore, it can be concluded that the presence of

295 microalgae was the cause of these antibiotics' removals.

296 Under acid conditions erythromycin converts rapidly to two metabolites:

297 anhydroerythromycin and erythromycin enol ether. These have the same chemical

298 formula and cannot be distinguished from each other by MS and were measured as one

299 entity. However, both are known to be biologically inactive [46]. The metabolites were

300 found in concentrations inversely proportional to erythromycin removals in all the

301 samples. Therefore, it seems that the microalgae enable a faster conversion of

302 erythromycin to the metabolite forms reducing antibacterial activity and thus,

303 decreasing the antimicrobial selection pressure, which is the on-going continual

304 exposure to antibiotics at sub-lethal or near lethal level and is the primary driver for

305 AMR development and maintenance.

306 One of the degradation products from clarithromycin found in the samples was

307 de(cladinosyl) clarithromycin, which is known to be pharmacologically active. This 
308 compound was observed in comparable amounts to clarithromycin (data not shown),

309 however, it remained constant in all the samples during the incubation period. In the

310 present study, even if the microalgae were not able to remove de(cladinosyl)

311 clarithromycin from wastewater, they did remove the parent compound, clarithromycin,

312 decreasing therefore, the overall antimicrobial selection pressure.

313 The mechanisms of pharmaceuticals removal by microalgae can include bioadsorption,

314 bioaccumulation and intracellular and extracellular biodegradation. Microalgae

315 bioadsoption of PRs is extracellular, therefore, the sorption process varies significantly

316 according to the hydrophobicity, structure, and functional groups of different PRs and

317 microalgae species [2]. In the present study, the concentration of erythromycin and

318 clarithromycin at the microalgae cell walls was analysed after the incubation period and

319 we did not find any trace of these antibiotics. This indicates that microalgae

320 bioadsorption was not the cause of erythromycin and clarithromycin removals.

321 Microalgae can also take up organic pollutants along with growth nutrients through

322 bioaccumulation [2]. In this study, microalgae cells were disrupted and analysed; no

323 erythromycin or clarithromycin was observed in the cell biomass, indicating that

324 microalgae bioaccumulation was not the cause of these antibiotics' removal either.

325 By process of elimination, it therefore, seems that biodegradation by microalgae was the

326 means of erythromycin and clarithromycin removal in these experiments.

327 This conclusion is supported by the fact that in samples with a very high concentration

328 of PRs, CHigh, where the microalgae suffered a severe inhibition, the concentrations of

329 the two antibiotics were similar in samples with and without microalgae (Figure 2).

330 In summary, it can be concluded that Chlamydomonas acidophila seems to degrade and

331 reduce antibacterial activity of the antibiotics erythromycin and clarithromycin and

332 enhances their removal from wastewater by $93-65 \%$ and $64-50 \%$ respectively. 
334 acidophila

335 Experimental data on cell growth and nutrients concentration dynamics in SM, WW,

336 WW+Met, CHigh and CModerate with and without microalgae samples during Phase 1

337 are shown in Fig. 3.

338 A pH-dependent equilibrium exists between the soluble ammonium ion $\left(\mathrm{NH}_{4}{ }^{+}\right)$and

339 dissolved molecular ammonia $\left(\mathrm{NH}_{3}\right)$. High $\mathrm{pH}$ favours ammonia volatilization by

340 driving the equilibrium between $\mathrm{NH}_{3}$ and $\mathrm{NH}_{4}{ }^{+}$to molecular ammonia [47]. Also, when

341 the $\mathrm{pH}$ is high, orthophosphate can be easily removed from wastewater by precipitation

342 as calcium and magnesium salts $[48,49]$. In the present study, the $\mathrm{pH}$ remained below 3

343 in all samples during the incubation, due to the acidophilic tendency of the microalgae

344 tested, and in samples without microalgae, cells and nutrient concentrations remained

345 constant during the incubation. Therefore, it can be assumed that any decrease in

346 nutrients $(\mathrm{N}, \mathrm{P})$ concentration in the rest of the samples was entirely attributed to their

347 assimilation by microalgae.

348 No significant differences in ammonium and phosphate removal rates were observed

349 between SM samples and WW samples, both achieving values of around $9 \mathrm{mgNH}_{4} \mathrm{~L}^{-1} \mathrm{~d}^{-}$

$350{ }^{1}$ and $3 \mathrm{mgPO}_{4} \mathrm{~L}^{-1} \mathrm{~d}^{-1}$, indicating that the microalgae were not affected by the presence

351 of wastewater. It is acknowledged that light availability is one of the greatest challenges

352 for microalgae cultivation and a high photosynthetic efficiency is essential to decrease

353 the costs of microalgal biomass production. Based on the results obtained in these

354 experiments, it seems that at this low light intensity $\left(43 \mu \mathrm{mol}\right.$ photons $\left.\mathrm{m}^{-2} \mathrm{~s}^{-1}\right), C$.

355 acidophila's growth rate was higher than other species used for wastewater treatment.

356 Furthermore, the ammonium removal efficiencies were similar to those reported in

357 studies with other microalgae in which ammonia volatization and phosphate 
358 precipitation was controlled by $\mathrm{pH}[50,51]$. The phosphate recoveries were slightly

359 higher than reported by Franchino et al. [51] using Neochloris oleabundans, Chlorella

360 vulgaris and Scenedesmus obliquus, who achieved up to $1.13,1.96$ and $1.50 \mathrm{mg} \mathrm{PO}_{4} \mathrm{~L}^{-1}$

$361 \mathrm{~d}^{-1}$ respectively, and Aslan and Kapdan [50] using Chlorella vulgaris, who achieved 1.8

$362 \mathrm{mg} \mathrm{PO} \mathrm{L}^{-1} \mathrm{~d}^{-1}$. Therefore, C. acidophila has shown promise as an agent to recover

363 nutrients under very low light intensities.

364 FIGURE 3

365 Regarding the effect of PR on growth, CModerate showed a typical batch growth with

366 an exponential increase of the cell concentration similar to the samples in standard

367 growing media (SM) and wastewater without PRs (WW) (Figure 3). Furthermore, no

368 significant differences were observed in nutrient removal rates when comparing

369 CModerate, SM and WW. This means that C. acidophila was not affected by PR

370 concentrations greatly exceeding environmentally relevant concentrations high levels

371 reported in the literature.

372 However, at the highest PR concentration (CHigh) cell growth was highly suppressed

373 and nutrients removal non-existent, which is consistent with pronounced inhibition.

374 This inhibition could be caused by a high concentration of pharmaceuticals such as

375 clarithromycin and erythromycin; Half Maximal Effective Concentration (EC50) values

376 of $12-46 \mu \mathrm{g} / \mathrm{L}$ and $20-366 \mu \mathrm{g} / \mathrm{L}$ and No Observed Effect Concentrations (NOEC)

377 values of $<40 \mu \mathrm{g} / \mathrm{L}$ and $10 \mu \mathrm{g} / \mathrm{L}$, respectively, are reported for green algae [52-56], so

378 that the antibiotics, alone or in association with other pharmaceuticals, could have an

379 effect on the microalgae. Furthermore, the high concentration of methanol added in the

380 dosing of these high concentration of pharmaceuticals might also had an effect on this

381 inhibition, as the cell growth and nutrients removals in samples WW+Met were slightly

382 different to the samples where the microalgae did not suffer any inhibition (Figure 3). 
383 It is important to point out that the high concentrations added in CHigh samples were

384 selected in order to stress the system to the limit (at 1,000-fold the highest

385 concentrations reported in literature) and therefore are unlikely to be found in any

386 wastewater treatment plant.

387 Experimental data on cell growth and nutrients concentration dynamics in SM, WW

388 environmentally relevant concentrations that can be found in any WWTP (CEnv) with

389 and without microalgae samples (Phase 2) are shown in Fig. 4.

390 FIGURE 4

391 CEnv showed similar growth and nutrients removals to the samples in standard growing 392 media (SM) and wastewater without PRs (WW) (Figure 4). Furthermore, no significant

393 differences were observed when comparing these data with CModerate (Figure 3).

394 Therefore, based on the obtained results, it can be stated that $C$. acidophila does not

395 seem to be affected by the presence of these 8 pharmaceuticals in wastewater at the

396 maximum concentrations detected in urban effluents. Given that the PR concentration

397 margin for when the microalgae started to show signs of inhibition is very wide (higher

398 than the concentration added in samples CModerate), it seems that C. acidophila is very

399 resistant to these micropollutants and therefore suitable for application in wastewater

400 treatment, even though long term exposure experiments should be carried out to verify

401 the chronic resistance ability of this species.

402 4. Conclusions

403 Chlamydomonas acidophila seems resistant to the studied pharmaceuticals and to be

404 able to degrade the antibiotics erythromycin and clarithromycin, two of the three

405 macrolide antibiotics in the Watch List, better than other species. Reducing these

406 compounds from wastewater, the antimicrobial selection pressure decreases, which is

407 the on-going continual exposure to low levels of antibiotics and is the primary driver for 
408 AMR development and maintenance. Furthermore, this microalga exhibited a high

409 assimilation of ammonium and phosphates reaching values of around $9 \mathrm{mgNH}_{4} \mathrm{~L}^{-1} \mathrm{~d}^{-1}$

410 and $3 \mathrm{mgPO}_{4} \mathrm{~L}^{-1} \mathrm{~d}^{-1}$ compared to other species and it does not seem to be affected by the

411 presence of atenolol, caffeine, carbamazepine, clarithromycin, erythromycin, lidocaine,

412 propranolol and simvastatin in wastewater at concentrations well above those detected

413 in urban effluents. Therefore, Chlamydomonas acidophila appears to be a promising

414 agent for wastewater treatment, also contributing to the achievement of phosphate and

415 ammonium standards pertaining to both discharge consents and WFD status

416 assessments, and mitigate eutrophication issues in receiving waters. Further long term

417 exposure experiments should be carried out to verify the chronic resistance ability and

418 antibiotics' removals of this species.

\section{Acknowledgements}

420 This work was financially supported by the European Union funding Marie

number DLV-661427.

423 The authors of this manuscript have no conflict of interest to declare.

\section{References}

425 [1] K. Helwig, C. Hunter, J. MacLachkan, M. McNaughtan, J. Roberts, A.
Cornelissen, C. Dagot, H. Evenblij, K. Klepiszewski, S. Lyko, I. Nafo, C.

McArdell, S. Venditti, O. Pahl, Micropollutant Point Sources in the Built

Environment: Identification and Monitoring of Priority Pharmaceutical

Substances in Hospital Effluents, J. Environ. Anal. Toxicol. 3 (2013). doi:http://dx.doi.org/10.4172/2161-0525.1000177.

[2] J.Q. Xiong, M.B. Kurade, B.H. Jeon, Can Microalgae Remove Pharmaceutical Contaminants from Water?, Trends Biotechnol. xx (2017) 1-15. 
doi:10.1016/j.tibtech.2017.09.003.

434 [3] K. Helwig, C. Hunter, M. McNaughtan, J. Roberts, O. Pahl, Ranking prescribed pharmaceuticals in terms of environmental risk: Inclusion of hospital data and the importance of regular review., Environ. Toxicol. Chem. 35 (2016) 1043-1050. doi:10.1002/etc.3302.

[4] P. Verlicchi, M. Al Aukidy, E. Zambello, Occurrence of pharmaceutical compounds in urban wastewater: Removal, mass load and environmental risk after a secondary treatment-A review, Sci. Total Environ. 429 (2012) 123-155. doi:10.1016/j.scitotenv.2012.04.028.

[5] M. Gardner, V. Jones, S. Comber, M.D. Scrimshaw, T. Coello-Garcia, E. Cartmell, J. Lester, B. Ellor, Performance of UK wastewater treatment works with respect to trace contaminants., Sci. Total Environ. 456-457 (2013) 359-369. doi:10.1016/j.scitotenv.2013.03.088.

[6] Commission Implementing Decision (EU) 2018/840 of 5 June 2018 establishing a watch list of substances for Union-wide monitoring in the field of water policy pursuant to Directive 2008/105/EC of the European Parliament and of the Council and repealing Comm, Off. J. Eur. Communitites. (2018) 9-12.

[7] Centre for Disease Dynamics, The State of the Worlds Antibiotics, Washington DC and New Delhi, 2015. https://cddep.org/publications/state_worlds_antibiotics_2015/.

[8] A.M.P.T. Pereira, L.J.G. Silva, L.M. Meisel, C.M. Lino, A. Pena, Environmental impact of pharmaceuticals from Portuguese wastewaters: geographical and seasonal occurrence, removal and risk assessment, Environ. Res. 136 (2015) 108-119. doi:https://doi.org/10.1016/j.envres.2014.09.041.

[9] N.P. Marathe, C. Pal, S.S. Gaikwad, V. Jonsson, E. Kristiansson, D.G.J. Larsson, 
Untreated urban waste contaminates Indian river sediments with resistance genes

to last resort antibiotics, Water Res. 124 (2017) 388-397.

460

doi:https://doi.org/10.1016/j.watres.2017.07.060.

461

[10] T. Stalder, M. Alrhmoun, J.-N. Louvet, M. Casellas, C. Maftah, C. Carrion, M.-

N. Pons, O. Pahl, M.-C. Ploy, C. Dagot, Dynamic assessment of the floc morphology, bacterial diversity, and integron content of an activated sludge reactor processing hospital effluent., Environ. Sci. Technol. 47 (2013) 79097917. doi:10.1021/es4008646.

466

467

468

469

470

[11] A. Escudero, F. Blanco, A. Lacalle, M. Pinto, Ammonium removal from anaerobically treated effluent by Chlamydomonas acidophila, Bioresour. Technol. 153 (2014). doi:10.1016/j.biortech.2013.11.076.

[12] M. Cuaresma, C. Casal, E. Forjan, C. Vilchez, Productivity and selective accumulation of carotenoids of the novel extremophile microalga Chlamydomonas acidophila grown with different carbon sources in batch systems., J. Ind. Microbiol. Biotechnol. 38 (2011) 167-177. doi:10.1007/s10295010-0841-3.

[13] J. Tittel, V. Bissinger, U. Gaedke, N. Kamjunke, Inorganic carbon limitation and mixotrophic growth in Chlamydomonas from an acidic mining lake, Protist. 156 (2005) 63-75. doi:10.1016/j.protis.2004.09.001.

[14] S.R. Subashchandrabose, B. Ramakrishnan, M. Megharaj, K. Venkateswarlu, R. Naidu, Mixotrophic cyanobacteria and microalgae as distinctive biological agents for organic pollutant degradation, Environ. Int. 51 (2013) 59-72. doi:https://doi.org/10.1016/j.envint.2012.10.007.

[15] G. Skouteris, D. Hermosilla, P. López, C. Negro, Á. Blanco, Anaerobic membrane bioreactors for wastewater treatment: A review, Chem. Eng. J. 198- 
199 (2012) 138-148. doi:10.1016/j.cej.2012.05.070.

484 [16] K. Möller, T. Müller, Effects of anaerobic digestion on digestate nutrient availability and crop growth: A review, Eng. Life Sci. 12 (2012) 242-257. doi:10.1002/elsc.201100085.

[17] Council directive of 21 May concerning urban wastewater treatment (91/271/ECC), (1991). https://eur-lex.europa.eu/legalcontent/EN/TXT/?qid=1576233004107\&uri=CELEX:31991L0271.

[18] Council Directive 91/676/EEC of 12 December concerning the protection of waters against pollution caused by nitrates from agricultural sources., (1991). https://eur-lex.europa.eu/legal-content/EN/ALL/?uri=CELEX\%3A31991L0676.

[19] Directive 2000/60/EC of the European Parliament and of the Council of 23 October 2000 establishing a framework for Community action in the field of water policy., (2000). https://eur-lex.europa.eu/legalcontent/EN/TXT/?qid=1576233091898\&uri=CELEX:32000L0060.

[20] OECD, Guideline for the testing of chemicals 303 A. Simulation test- Aerobic sewage treatment activated sludge unit. Organization of the Economic Collaboration \& Development., Paris, France., 2001.

[21] N. Vieno, T. Tuhkanen, L. Kronberg, Elimination of pharmaceuticals in sewage treatment plants in Finland, Water Res. 41 (2007) 1001-1012. doi:https://doi.org/10.1016/j.watres.2006.12.017.

[22] S.J. Khan, J.E. Ongerth, Modelling of pharmaceutical residues in Australian sewage by quantities of use and fugacity calculations, Chemosphere. 54 (2004) 355-367. doi:https://doi.org/10.1016/j.chemosphere.2003.07.001.

[23] T.S. Oliveira, M. Murphy, N. Mendola, V. Wong, D. Carlson, L. Waring, Characterization of Pharmaceuticals and Personal Care products in hospital 
508 effluent and waste water influent/effluent by direct-injection LC-MS-MS, Sci.

$509 \quad$ Total Environ. 518-519 (2015) 459-478.

$510 \quad$ doi:https://doi.org/10.1016/j.scitotenv.2015.02.104.

511 [24] J.L. Santos, I. Aparicio, E. Alonso, Occurrence and risk assessment of pharmaceutically active compounds in wastewater treatment plants. A case study: Seville city (Spain), Environ. Int. 33 (2007) 596-601. doi:https://doi.org/10.1016/j.envint.2006.09.014.

[25] W. Qi, H. Singer, M. Berg, B. Müller, B. Pernet-Coudrier, H. Liu, J. Qu, Elimination of polar micropollutants and anthropogenic markers by wastewater treatment in Beijing, China, Chemosphere. 119 (2015) 1054-1061. doi:https://doi.org/10.1016/j.chemosphere.2014.09.027.

[26] S. Weigel, U. Berger, E. Jensen, R. Kallenborn, H. Thoresen, H. Hühnerfuss, Determination of selected pharmaceuticals and caffeine in sewage and seawater from Troms $\varnothing /$ Norway with emphasis on ibuprofen and its metabolites, Chemosphere. 56 (2004) 583-592. doi:https://doi.org/10.1016/j.chemosphere.2004.04.015.

[27] T. Azuma, N. Arima, A. Tsukada, S. Hirami, R. Matsuoka, R. Moriwake, H. Ishiuchi, T. Inoyama, Y. Teranishi, M. Yamaoka, Y. Mino, T. Hayashi, Y. Fujita, M. Masada, Detection of pharmaceuticals and phytochemicals together with their metabolites in hospital effluents in Japan, and their contribution to sewage treatment plant influents, Sci. Total Environ. 548-549 (2016) 189-197. doi:https://doi.org/10.1016/j.scitotenv.2015.12.157.

[28] P. Guerra, M. Kim, A. Shah, M. Alaee, S.A. Smyth, Occurrence and fate of antibiotic, analgesic/anti-inflammatory, and antifungal compounds in five wastewater treatment processes, Sci. Total Environ. 473-474 (2014) 235-243. 
doi:https://doi.org/10.1016/j.scitotenv.2013.12.008.

534 [29] Q. Sui, J. Huang, S. Deng, G. Yu, Q. Fan, Occurrence and removal of pharmaceuticals, caffeine and DEET in wastewater treatment plants of Beijing, China, Water Res. 44 (2010) 417-426. doi:https://doi.org/10.1016/j.watres.2009.07.010.

538 [30] E.N. Evgenidou, I.K. Konstantinou, D.A. Lambropoulou, Occurrence and 539 removal of transformation products of PPCPs and illicit drugs in wastewaters: A review, Sci. Total Environ. 505 (2015) 905-926. doi:https://doi.org/10.1016/j.scitotenv.2014.10.021.

[31] R. Rosal, A. Rodríguez, J.A. Perdigón-Melón, A. Petre, E. García-Calvo, M.J. Gómez, A. Agüera, A.R. Fernández-Alba, Occurrence of emerging pollutants in urban wastewater and their removal through biological treatment followed by ozonation, Water Res. 44 (2010) 578-588. doi:https://doi.org/10.1016/j.watres.2009.07.004.

[32] P.C. Rúa-Gómez, A.A. Guedez, C.O. Ania, W. Püttmann, Upgrading of Wastewater Treatment Plants Through the Use of Unconventional Treatment Technologies: Removal of Lidocaine, Tramadol, Venlafaxine and Their Metabolites, Water. 4 (2012) 650-669. doi:10.3390/w4030650.

[33] P. Vazquez-Roig, V. Andreu, C. Blasco, Y. Picó, Risk assessment on the presence of pharmaceuticals in sediments, soils and waters of the Pego-Oliva Marshlands (Valencia, eastern Spain), Sci. Total Environ. 440 (2012) 24-32. doi:https://doi.org/10.1016/j.scitotenv.2012.08.036.

[34] T. Deblonde, C. Cossu-Leguille, P. Hartemann, Emerging pollutants in wastewater: A review of the literature, Int. J. Hyg. Environ. Health. 214 (2011) 442-448. doi:https://doi.org/10.1016/j.ijheh.2011.08.002. 
558 [35] K.J. Ottmar, L.M. Colosi, J.A. Smith, Fate and transport of atorvastatin and 559 simvastatin drugs during conventional wastewater treatment, Chemosphere. 88 (2012) 1184-1189. doi:https://doi.org/10.1016/j.chemosphere.2012.03.066.

561 [36] A.P.H.A. APHA, Standard Methods for the Examination of Water and 562 Wastewater, Washington, USA, 2012.

563 [37] O.D.W. Folin, Nitrogen Determinations by Direct Nesslerization, J. Biol. Chem. $564 \quad 26(1916) 473-489$.

565 [38] V. Matamoros, E. Uggetti, J. García, J.M. Bayona, Assessment of the 566 mechanisms involved in the removal of emerging contaminants by microalgae 567 from wastewater: A laboratory scale study, J. Hazard. Mater. 301 (2016) 197$568 \quad$ 205. doi:10.1016/j.jhazmat.2015.08.050.

569 [39] D.Q. Zhang, T. Hua, R.M. Gersberg, J. Zhu, W. Jern, S. Keat, Fate of caffeine in 570 mesocosms wetland planted with Scirpus validus, Chemosphere. 90 (2013) $571 \quad$ 1568-1572. doi:10.1016/j.chemosphere.2012.09.059.

572 [40] T.R. Pedersen, J.A. Tobert, Simvastatin: a review, Expert Opin. Pharmacother. 5 573 (2004) 2583-2596. doi:10.1517/14656566.5.12.2583.

574 [41] A. Solé, V. Matamoros, Removal of endocrine disrupting compounds from 575 wastewater by microalgae co-immobilized in alginate beads, Chemosphere. 164 576 (2016) 516-523. doi:10.1016/j.chemosphere.2016.08.047.

577 [42] A. de Wilt, A. Butkovskyi, K. Tuantet, L.H. Leal, T. V. Fernandes, A. 578 Langenhoff, G. Zeeman, Micropollutant removal in an algal treatment system fed 579 with source separated wastewater streams, J. Hazard. Mater. 304 (2016) 84-92. 580 doi:10.1016/j.jhazmat.2015.10.033.

581 [43] S. Rühmland, A. Wick, T.A. Ternes, M. Barjenbruch, Fate of pharmaceuticals in 582 a subsurface flow constructed wetland and two ponds, Ecol. Eng. 80 (2015) 125- 
583
584 [44] G. Zhou, G. Ying, S. Liu, L. Zhou, Z. Chen, Simultaneous removal of inorganic and organic compounds in wastewater by Environmental Science Processes \& Impacts compounds in wastewater by freshwater green, Environ. Sci. Process. Impacts. 16 (2014) 2018-2027. doi:10.1039/C4EM00094C.

[45] A. Hom-Diaz, A. Jaén-Gil, I. Bello-Laserna, S. Rodríguez-Mozaz, T. Vicent, D. Barceló, P. Blánquez, Performance of a microalgal photobioreactor treating toilet wastewater: Pharmaceutically active compound removal and biomass harvesting, Sci. Total Environ. 592 (2017) 1-11. doi:https://doi.org/10.1016/j.scitotenv.2017.02.224.

[46] A. Hassanzadeh, J. Barber, G.A. Morris, P.A. Gorry, Mechanism for the degradation of erythromycin A and erythromycin A 2'-ethyl succinate in acidic aqueous solution, J. Phys. Chem. A. 111 (2007) 10098-10104. doi:10.1021/jp073030y.

[47] L. Lin, S. Yuan, J. Chen, Z. Xu, X. Lu, Removal of ammonia nitrogen in wastewater by microwave radiation, J. Hazard. Mater. 161 (2009) 1063-1068. doi:https://doi.org/10.1016/j.jhazmat.2008.04.053.

[48] M.E. Martinez, S. Sanchez, J.M. Jimenez, F. Yousfi, L. Munoz, Nitrogen and phosphorus removal from urban wastewater by the microalga Scenedesmus obliquus, Bioresour Technol. 73 (2000). doi:10.1016/S0960-8524(99)00121-2.

[49] F. Iasimone, A. Panico, V. De Felice, F. Fantasma, M. Iorizzi, F. Pirozzi, Effect of light intensity and nutrients supply on microalgae cultivated in urban wastewater: Biomass production, lipids accumulation and settleability characteristics, J. Environ. Manage. 223 (2018) 1078-1085. doi:10.1016/j.jenvman.2018.07.024. 
608 [50] S. Aslan, I.K. Kapdan, Batch kinetics of nitrogen and phosphorus removal from 609 synthetic wastewater by algae, Ecol. Eng. 28 (2006) 64-70.

610 doi:10.1016/j.ecoleng.2006.04.003.

611 [51] M. Franchino, E. Comino, F. Bona, V.A. Riggio, Growth of three microalgae 612 strains and nutrient removal from an agro-zootechnical digestate, Chemosphere. $61392(2013)$ 738-744. doi:10.1016/j.chemosphere.2013.04.023.

614 [52] A. Harada, K. Komori, N. Nakada, K. Kitamura, Y. Suzuki, Biological effects of 615 PPCPs on aquatic lives and evaluation of river waters, Water Sci. Technol. 58

616 (2008) 1541-1546.

617 [53] L.-H. Yang, G.-G. Ying, H.-C. Su, J.L. Strauber, M.S. Adams, M.T. Binet, 618 Growth-inhibiting effects of 12 antibacterial agents and their mixtures on the 619 freshwater microalga Pseudokirchnerella subcapitata, Environ. Toxicol. Chem. 620 27 (2008) 1201-1208.

[54] T. Ando, H. Nagase, A novel method using cyanobacteria for ecotoxicity test of veterinary, Environ. Toxicol. Chem. 26 (2007) 601-606.

[55] K. Eguchi, H. Nagase, M. Ozawa, Y.S. Endoh, K. Goto, K. Hirata, K. Miyamoto, H. Yoshimura, Evaluation of antimicrobial agents for veterinary use in the 625 ecotoxicity test using microalgae, Chemosphere. 57 (2004) 1733-1738. doi:10.1016/J.CHEMOSPHERE.2004.07.017.

627 [56] M. Isidori, M. Lavorgna, A. Nardelli, L. Pascarella, A. Parrella, Toxic and 628 genotoxic evaluation of six antibiotics on non-target organisms, Sci. Total 629 Environ. 346 (2005) 87-98. doi:10.1016/J.SCITOTENV.2004.11.017. 630 


\section{Figure captions}

632 Fig 1. Changes in concentrations of caffeine, simvastatin, lidocaine, carbamazepine,

633 atenolol and propanolol in the medium during the incubation in CModerate samples.

634 The changes in concentrations in CEnv and CHigh followed similar patterns (data not

635 shown). Each point represents the mean value from three replicate determinations with

636 standard deviation.

637 Fig 2. Removals of erythromycin and clarithromycin in the medium during incubation,

638 expressed as the ratio between their concentrations in the media $\left(\mathrm{C}_{\mathrm{x}}\right)$ and their initial

639 concentration $\left(\mathrm{C}_{0}\right)$. Each point represents mean value from three replicate

640 determinations with standard deviation.

641 Fig 3. Phase 1: Changes in cells, $\mathrm{NH}_{4}{ }^{+}$and $\mathrm{PO}_{4}{ }^{-3}$ concentration in the medium during

642 the incubation of SM, WW, WW+Met, CHigh and CModerate with and without

643 microalgae. Each point represents mean value from three replicate determinations with

644 standard deviation.

645 Fig 4. Phase 2: Changes in cells, $\mathrm{NH}_{4}{ }^{+}$and $\mathrm{PO}_{4}{ }^{-3}$ concentration in the medium during

646 the incubation of SM, WW and CEnv with and without microalgae. Each point

647 represents mean value from three replicate determinations with standard deviation. 


\section{References}

[1] G. Zhou, G. Ying, S. Liu, L. Zhou, Z. Chen, Simultaneous removal of inorganic and organic compounds in wastewater by Environmental Science Processes \& Impacts compounds in wastewater by freshwater green, Environ. Sci. Process. Impacts. 16 (2014) 2018-2027. doi:10.1039/C4EM00094C.

[2] S.N. Tolboom, D. Carrillo-Nieves, M. de Jesús Rostro-Alanis, R. de la Cruz Quiroz, D. Barceló, H.M.N. Iqbal, R. Parra-Saldivar, Algal-based removal strategies for hazardous contaminants from the environment - A review, Sci. Total Environ. 665 (2019) 358-366. doi:https://doi.org/10.1016/j.scitotenv.2019.02.129.

[3] I.A. Vasiliadou, R. Molina, F. Martinez, J.A. Melero, P.M. Stathopoulou, G. Tsiamis, Toxicity assessment of pharmaceutical compounds on mixed culture from activated sludge using respirometric technique: The role of microbial community structure, Sci. Total Environ. 630 (2018) 809-819. doi:10.1016/J.SCITOTENV.2018.02.095.

[4] P. Foladori, L. Bruni, S. Tamburini, Toxicant inhibition in activated sludge: Fractionation of the physiological status of bacteria, J. Hazard. Mater. 280 (2014) 758-766. doi:10.1016/J.JHAZMAT.2014.09.003.

[5] S. Aydin, Enhanced biodegradation of antibiotic combinations via the sequential treamten of the sludge resulting from pharmaceutical wastewater treatment using white-rot fungi Trametes versicolor and Bjerkandera adusta., Appl. Microbiol. Biotechnol. 100 (2016) 64916499. doi:https://doi.org/10.1016/j.watres.2016.10.046. 


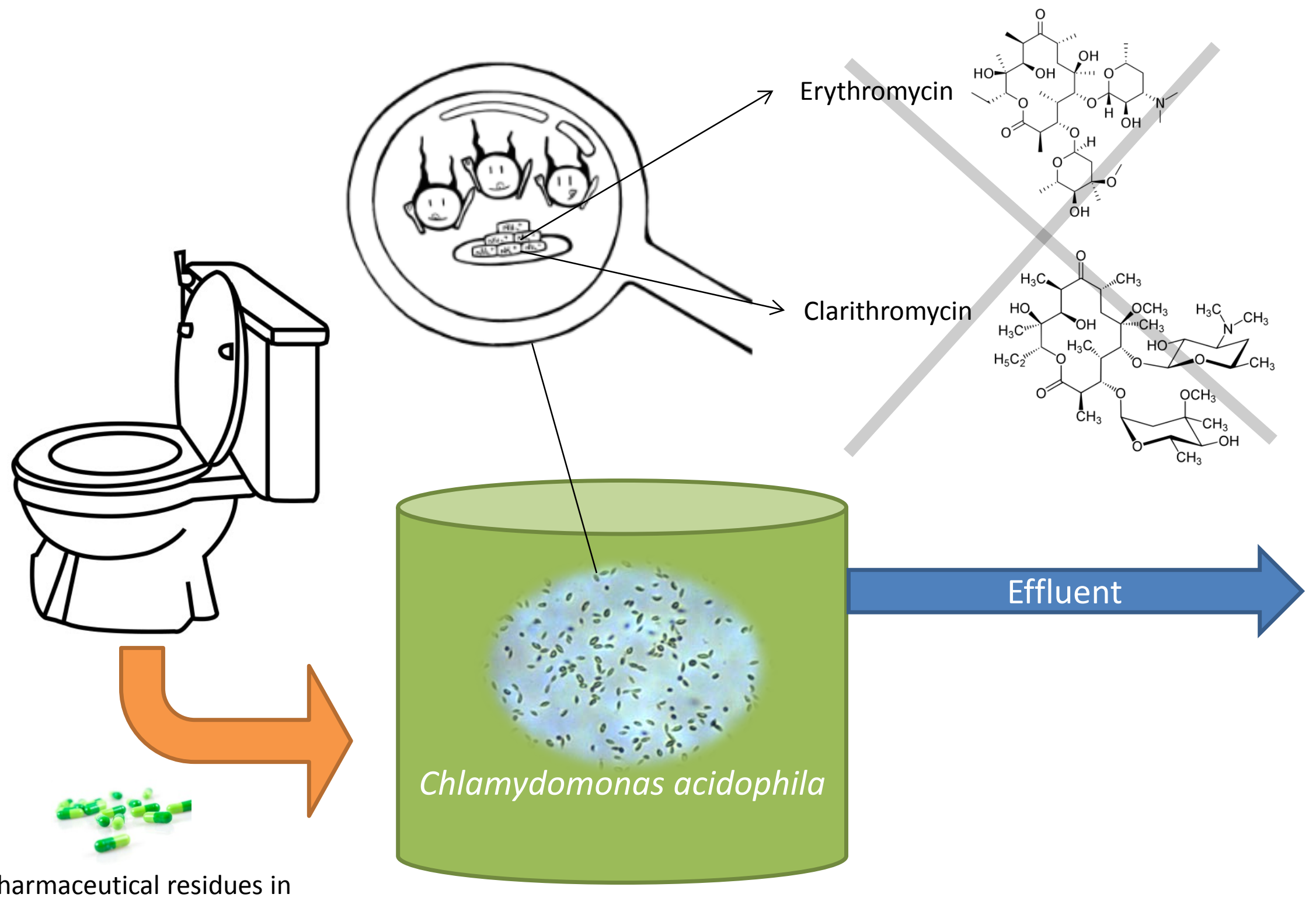

wastewater 
Click here to download high resolution image

Caffeine

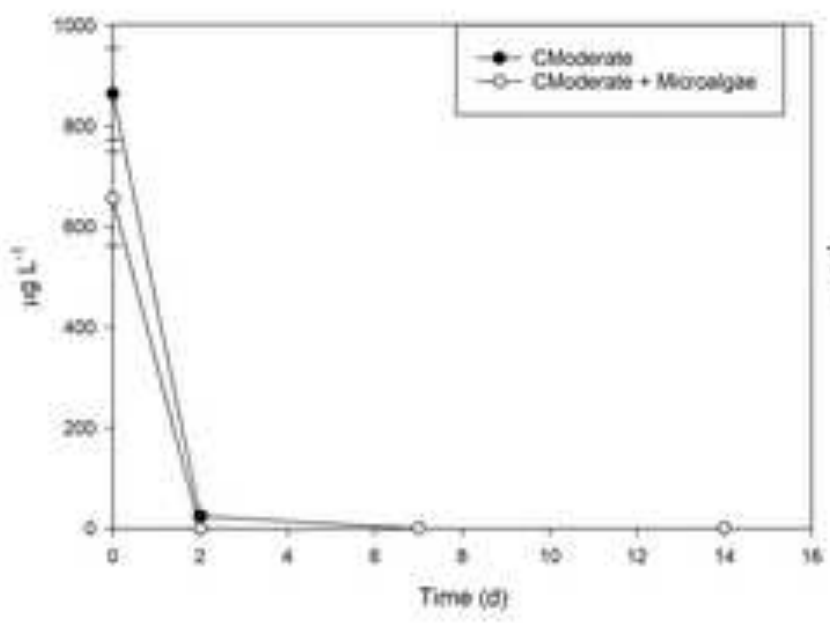

Carbamazepine

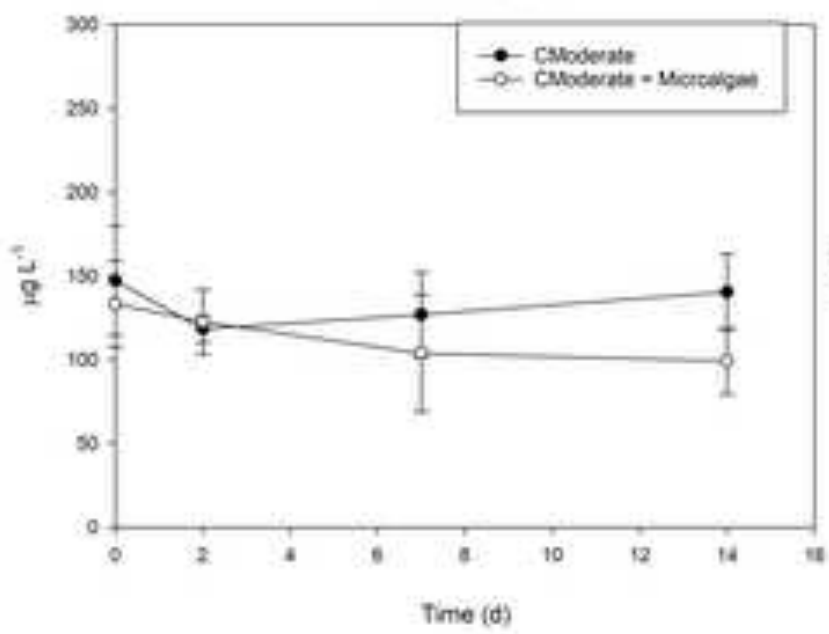

Atenold

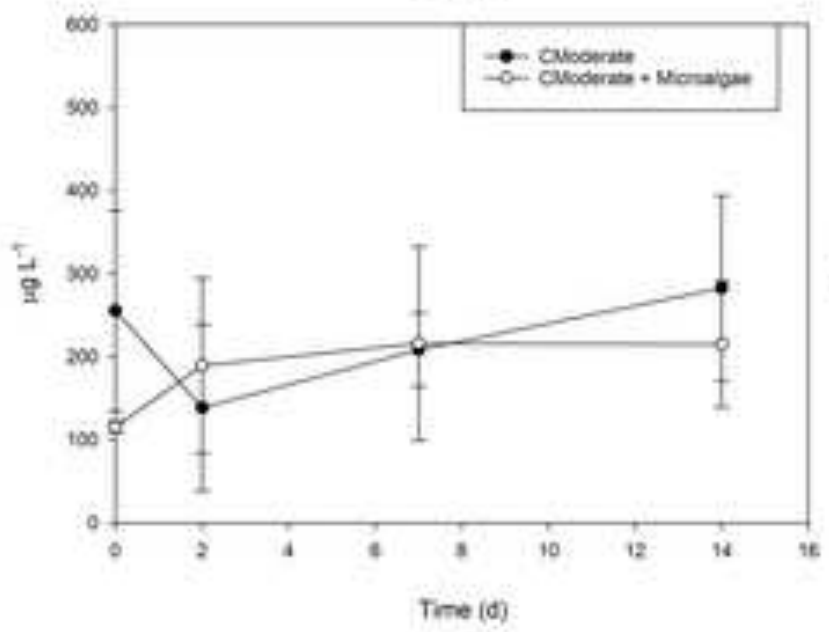

Simvastatin

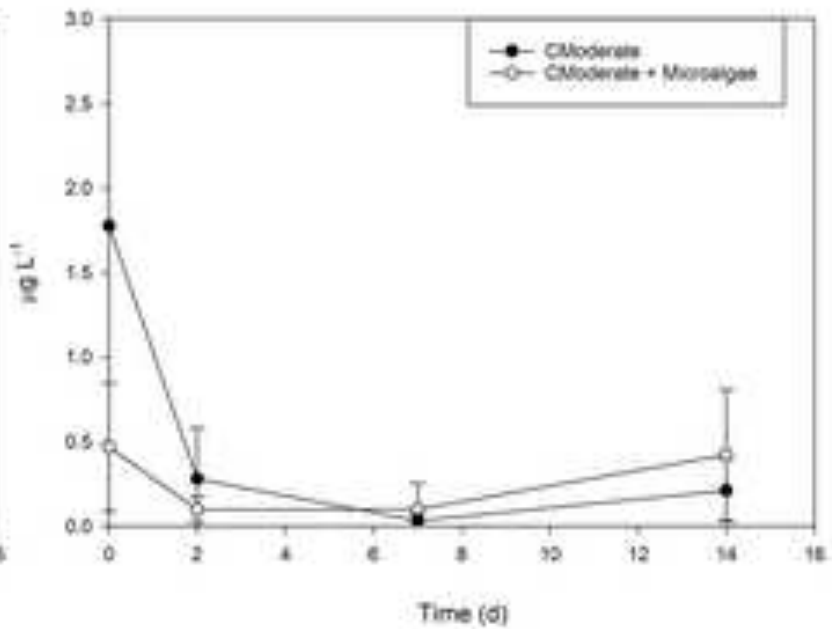

Lidocaine

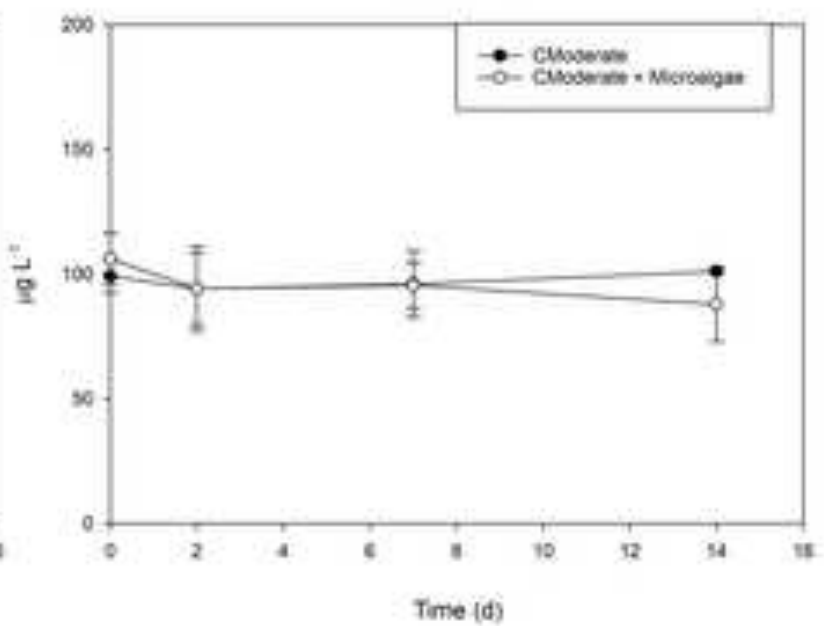

Propranolel

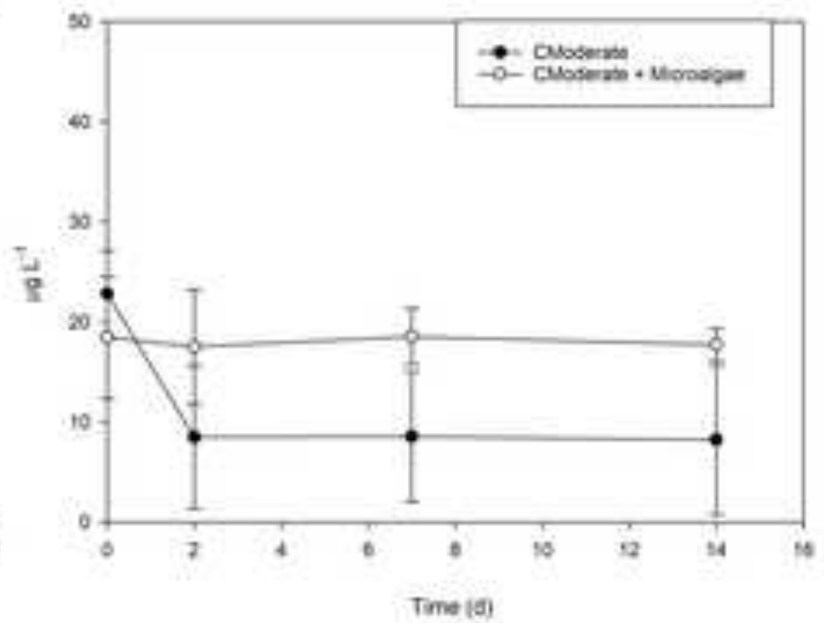


Click here to download high resolution image

Erythromycin

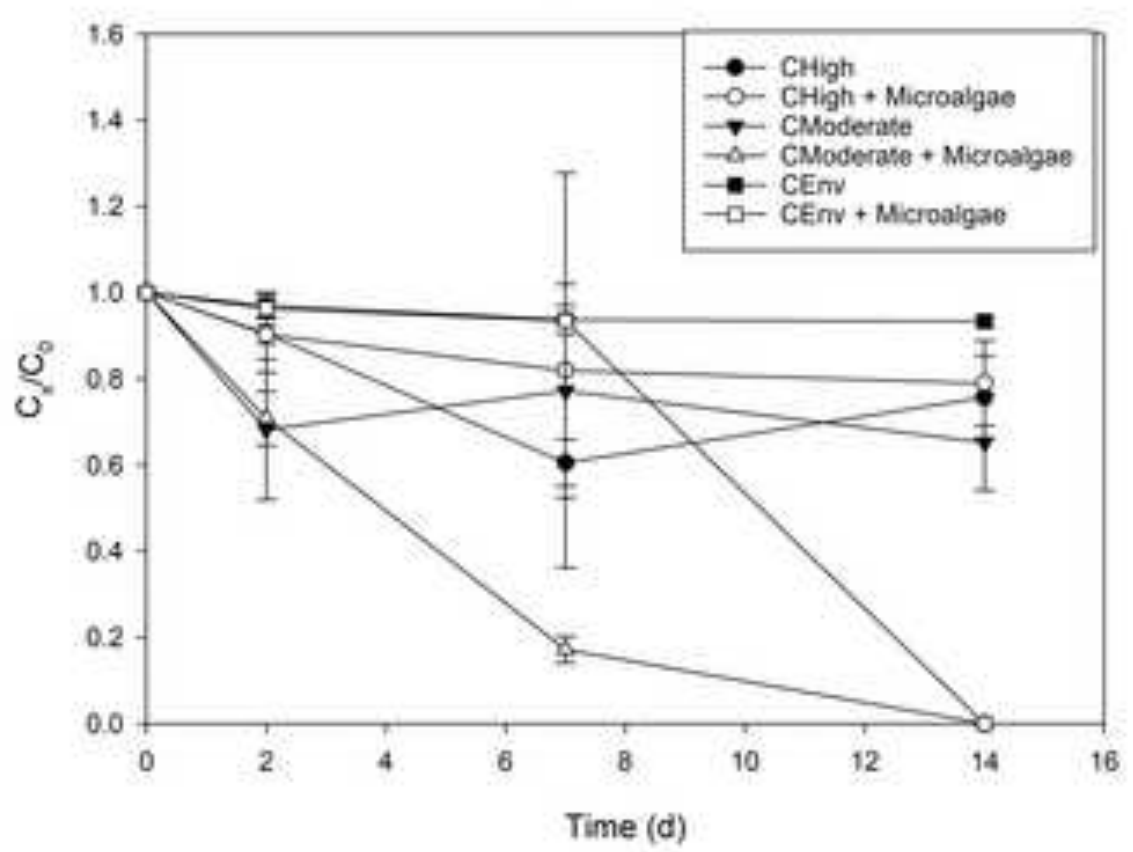

Clarithromycin

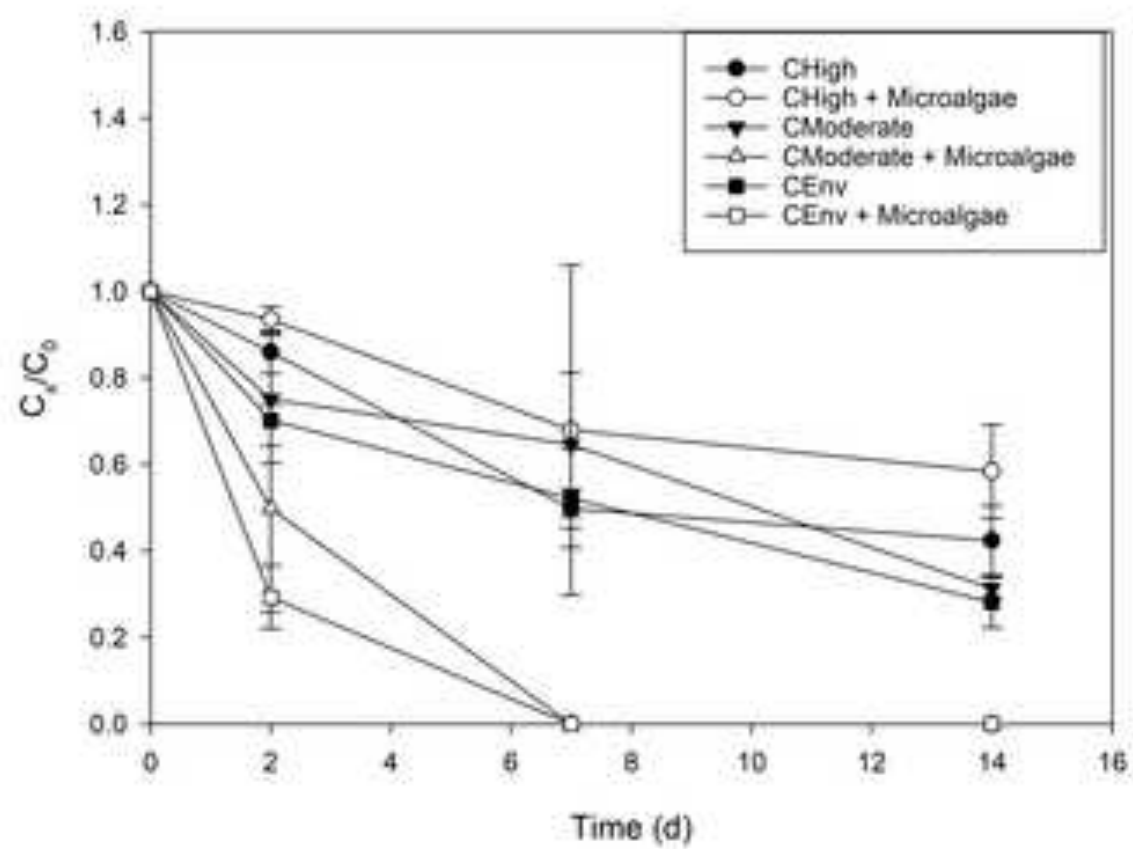


Figure 3

Click here to download high resolution image

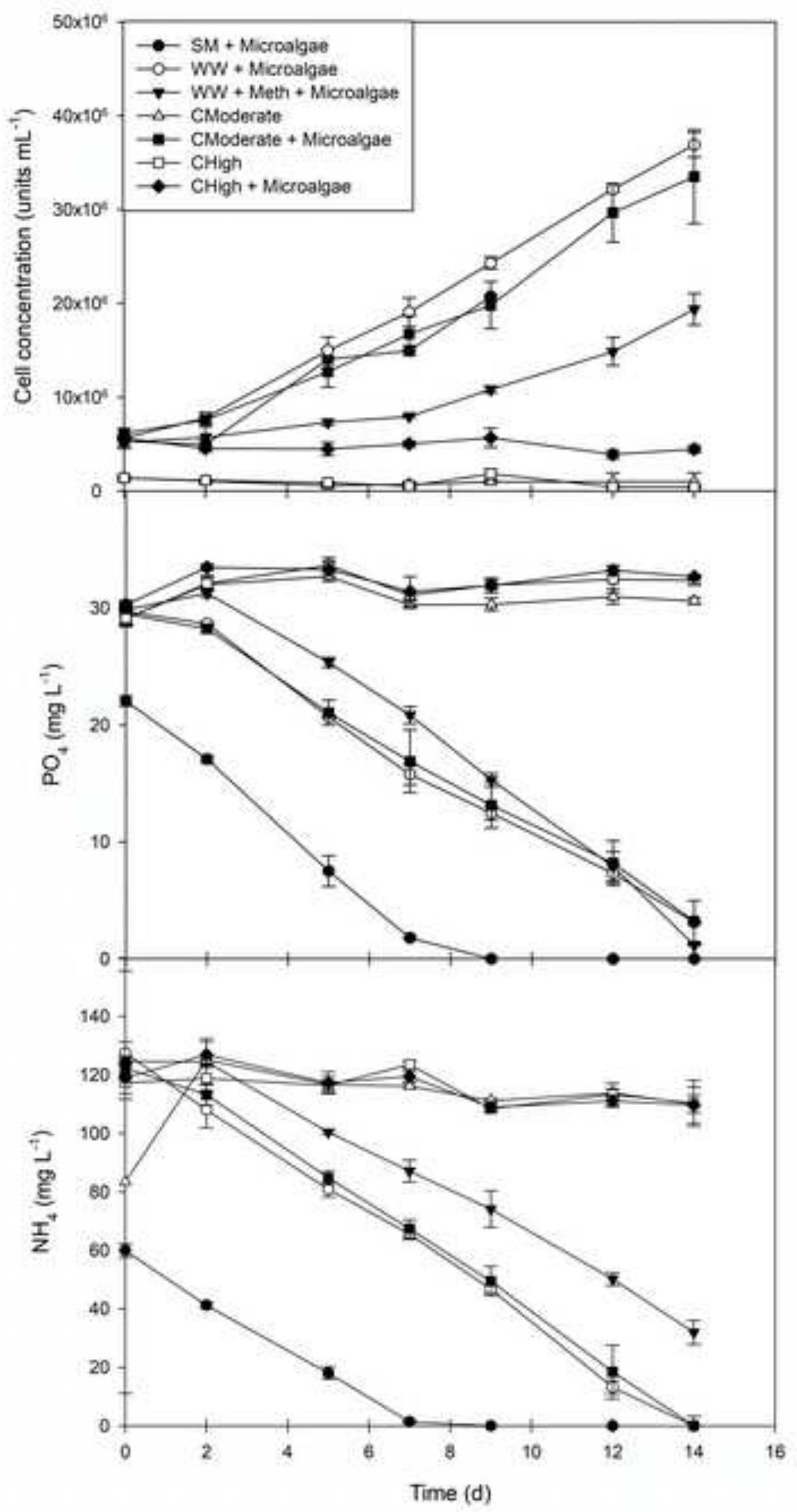


Figure 4

Click here to download high resolution image

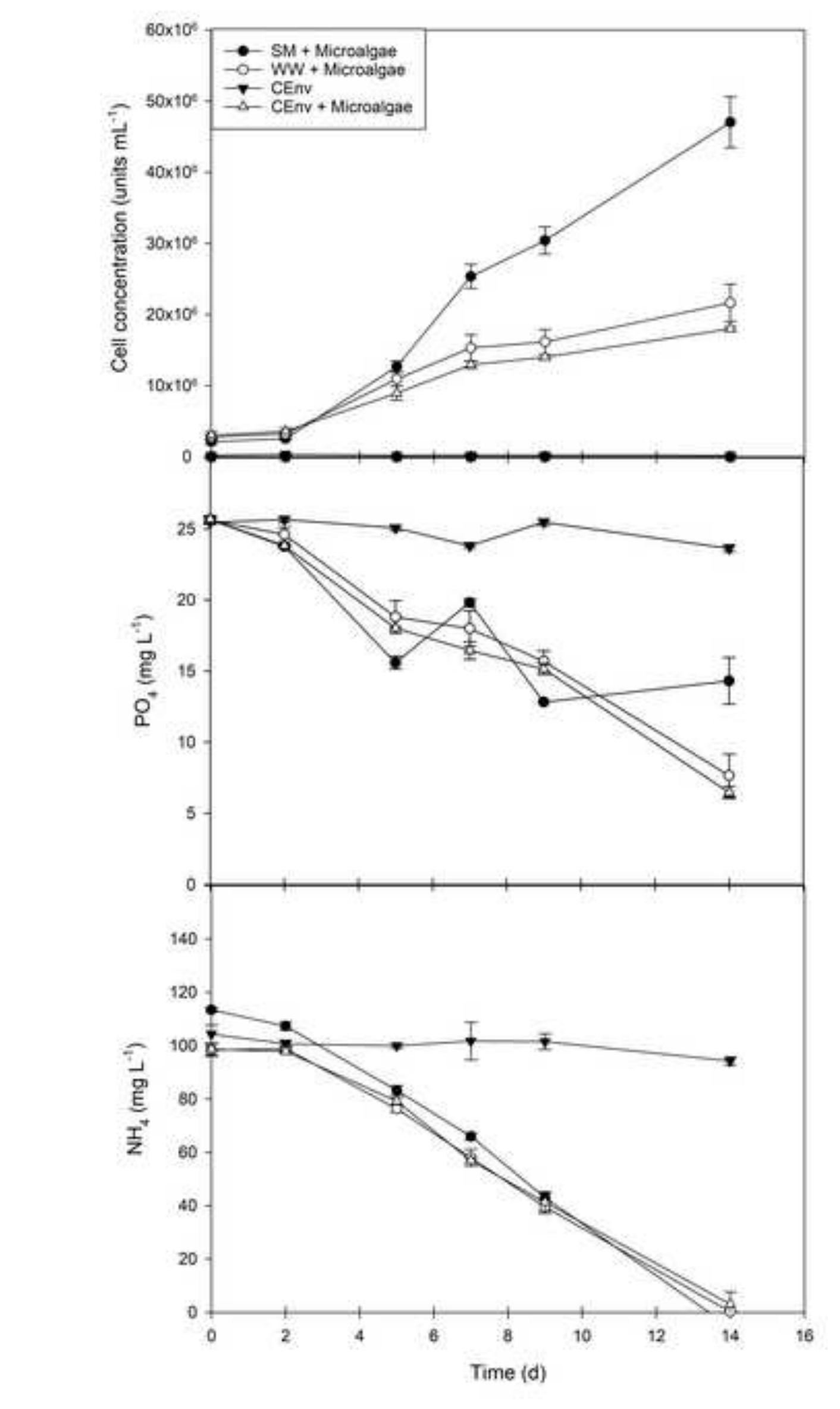

\section{.}


Table 1. Pharmaceutical concentrations studied in this assay.

\begin{tabular}{|c|c|c|c|c|c|}
\hline & & \multirow{2}{*}{\multicolumn{2}{|c|}{ Phase 1}} & \multirow{3}{*}{$\begin{array}{r}\text { Phase } 2 \\
\text { CEnv }^{\mathrm{c}}(\mu \mathrm{g} / \mathrm{L})\end{array}$} & \multirow[b]{3}{*}{ References } \\
\hline & & & & & \\
\hline Compound & $\begin{array}{l}\text { Reported wastewater } \\
\text { Concentrations }(\mu \mathrm{g} / \mathrm{L})\end{array}$ & $\mathrm{CHigh}^{\mathrm{a}}(\mu \mathrm{g} / \mathrm{L})$ & $\begin{array}{l}\text { CModerate }^{\mathrm{b}} \\
(\mu \mathrm{g} / \mathrm{L})\end{array}$ & & \\
\hline \multirow{3}{*}{ Atenolol } & $0.35-1.710$ & \multirow{3}{*}{6,030} & \multirow{3}{*}{350} & \multirow{3}{*}{6.03} & [21] \\
\hline & 3 & & & & [22] \\
\hline & $1.35-6.03$ & & & & [23] \\
\hline \multirow{3}{*}{ Caffeine } & $0.68-11.44$ & \multirow{3}{*}{54,700} & \multirow{3}{*}{680} & \multirow{3}{*}{54.70} & [24] \\
\hline & $22-25.9$ & & & & [25] \\
\hline & 54.7 & & & & [26] \\
\hline \multirow{3}{*}{ Clarithromycin } & 0.56 & \multirow{3}{*}{800} & \multirow{3}{*}{40} & \multirow{3}{*}{8.00} & [27] \\
\hline & $0.17-0.36$ & & & & [23] \\
\hline & $0.04-1.2-8$ & & & & [28] \\
\hline \multirow{4}{*}{ Carbamazepine } & 0.113 & \multirow{4}{*}{820} & \multirow{4}{*}{160} & \multirow{4}{*}{0.82} & [29] \\
\hline & $0.16-0.820$ & & & & [21] \\
\hline & $<2.15$ & & & & [24] \\
\hline & $0.16-0.57$ & & & & [23] \\
\hline \multirow{5}{*}{ Erythromycin } & 0.2 & \multirow{5}{*}{2,300} & \multirow{5}{*}{14} & \multirow{5}{*}{2.30} & [22] \\
\hline & 0.11 & & & & [23] \\
\hline & $0.014-0.092-0.6$ & & & & [28] \\
\hline & 1.2 & & & & [30] \\
\hline & 2.3 & & & & [31] \\
\hline \multirow{3}{*}{ Lidocaine } & $0.66-0.77$ & \multirow{3}{*}{770} & \multirow{3}{*}{70} & \multirow{3}{*}{0.77} & [23] \\
\hline & $0.13-0.18$ & & & & [21] \\
\hline & $0.07-0.27$ & & & & [32] \\
\hline \multirow{3}{*}{ Propranolol } & $0.03-0.07$ & \multirow{3}{*}{510} & \multirow{3}{*}{30} & & [23] \\
\hline & $0.001-0.017$ & & & 0.51 & [33] \\
\hline & $0.036-0.51$ & & & & [34] \\
\hline Cimuctin & 0.9 & & & & [22] \\
\hline Simvastatin & 1.23 & 8,500 & 900 & 8.50 & [35] \\
\hline & n.d.-2.65-8.5 & & & & [8] \\
\hline
\end{tabular}

(a) CHigh: Highest Reported Concentration x1000 ( $\mu \mathrm{g} / \mathrm{L})$

(b) CModerate: Lowest Reported Concentration x1000 ( $\mu \mathrm{g} / \mathrm{L})$

(c) CEnv: Highest Reported Concentration ( $\mu \mathrm{g} / \mathrm{L}$ ) 


\section{SUPPLEMENTARY INFORMATION}

Ionisation mode and transitions for quantitation of pharmaceuticals by high resolution mass spectrometry (HRMS).

\begin{tabular}{cccc} 
Pharmaceutical & $\begin{array}{c}\text { lonisation } \\
\text { mode }\end{array}$ & $\begin{array}{c}\text { Precursor } \\
\text { Ion }\end{array}$ & $\begin{array}{c}\text { Product } \\
\text { lon }\end{array}$ \\
\hline Atenolol & Positive & 267.17 & 190.0868 \\
Caffeine & Positive & 195.09 & 138.0663 \\
Clarithromycin & Positive & 748.48 & 158.118 \\
Carbamazepine & Positive & 237.1 & 194.0972 \\
Erythromycin & Positive & 734.47 & 158.1176 \\
Lidocaine & Positive & 235.18 & 86.0967 \\
Propranolol & Positive & 260.16 & 116.1071 \\
Simvastatin & Negative & 419.2792 & NA
\end{tabular}

